\title{
Significados de democracia para os sujeitos da Democracia Corinthiana ${ }^{1}$
}

\author{
Mariana Zuaneti Martins* \\ Heloisa Helena Baldy dos Reis ${ }^{* *}$
}

\begin{abstract}
Resumo: Esta pesquisa tem como tema central a Democracia Corinthiana, movimento de um grupo de jogadores e dirigentes do Sport Club Corinthians no período de 1981 a 1985. O objetivo deste artigo é examinar os significados atribuídos à democracia por jogadores, técnicos e dirigentes que foram sujeitos desse movimento. A partir da revisão bibliográfica sobre democracia, de duas entrevistas semiestruturadas e de pesquisa histórica em jornais, encontramos declarações fornecidas por esses sujeitos de como eles entendiam a democracia no movimento corinthiano. Como resultado, encontramos respostas que variavam tanto em termos de defesas de procedimentos das tomada de decisões, como de conteúdo das conquistas alcançadas, além de alguns pontos contraditórios a estes. Deste modo, não se pode afirmar um sentido unívoco de democracia na Democracia Corinthiana.
\end{abstract}

Palavras-chaves: Democracia Corinthiana. Sociologia do esporte; futebol; democracia.

\section{INTRODUÇÃO ${ }^{2}$}

Este artigo consiste em um recorte de uma pesquisa mais ampla sobre a Democracia Corinthiana ${ }^{3}$. Nosso objetivo é explorar os distintos significados do termo "democracia" para os sujeitos do

\footnotetext{
"Doutoranda do PPG em Educação Física. Universidade Estadual de Campinas (Unicamp). Campinas, SP, Brasil. E-mail: fale.com.marief@gmail.com

"Livre-Docente. Programa de Pós-Graduação em Educação Física. Universidade Estadual de Campinas (Unicamp). Campinas, SP, Brasil. E-mail: helobaldy@yahoo.com

${ }^{1}$ Pesquisa financiada pela CAPES.

${ }^{2}$ Os procedimentos empregados na pesquisa estão de acordo com os princípios éticos norteadores das Resoluções 196/96 e 251/97 do Conselho Nacional de Saúde.

${ }^{3} \mathrm{~A}$ expressão "Democracia Corinthiana" não foi cunhada como uma criação coletiva dos jogadores de futebol do Corinthians. O jornalista Juca Kfouri, num debate sobre os rumos do clube, a proferiu como se houvesse no Corinthians uma democracia. Após este ocorrido, o então publicitário do clube, Washington Olivetto, começou a utilizá-la para identificar o momento pelo qual passava a equipe, criando a marca "Democracia Corinthiana", que virou o nome do jornal institucional, inscritos de camisetas e das chapas de reeleição para as diretorias seguintes.
} 
movimento corinthiano. Este pode ser compreendido como as duas gestões do presidente Waldemar Pires à frente do Corinthians, ocorridas entre março de 1981 e março de 1985. Neste período, foram estabelecidas formas menos autoritárias de gestão do clube e da equipe, tonando-se possível a participação dos jogadores em processos de tomada de decisão. Ademais, a Democracia Corinthiana pode ser considerada um momento no qual se constituiu a possibilidade de uma maior conscientização política no futebol, uma vez que parte dos jogadores participaram também dos embates daquele contexto na campanha "Diretas-Já"4. O final da década de 1970 e início de 1980 foram marcadas pela ascensão dos movimentos sindicais e sociais no Brasil. Segundo Sader (2002, p. 30), esse período representava a criação de um "comportamento coletivo de contestação da ordem social vigente", em que surgem novos partidos políticos, novos movimentos sociais, com distintas identidades e matrizes discursivas. Neste cenário que se tornou possível o reconhecimento do jogador de futebol como cidadão e sua emergência como sujeito político.

A Democracia Corinthiana, situada neste contexto, suscita questões teóricas e práticas sobre o seu significado democrático. Conforme indica a literatura acadêmica sobre este contexto histórico, o entendimento da reabertura democrática era múltiplo para os diversos agentes políticos, desde aqueles que pensavam democracia como a distensão do regime militar - os próprios militares - quanto aqueles de oposição ao regime - uma franja que unia desde a oposição "interna" àquela mais radical (que se congregavam nas manifestações políticas da campanha das "Diretas-já") ${ }^{5}$. Inserida neste contexto, na Democracia Corinthiana também estavam contidas visões distintas sobre a democracia.

\footnotetext{
${ }^{4} \mathrm{~A}$ campanha intitulada de "Diretas-Já" reivindicava a retomada das eleições diretas para a presidência da república, ganhando fôlego a partir da criação de uma emenda, intitulada Dante de Oliveira, que reconstituiria essa forma de pleito, eliminando o colégio eleitoral indireto. (BERTONCELO, 2007).

${ }^{5}$ Nossa principal referência para o entendimento da pluralidade e complexidade dos sentidos políticos da década de 1980 foram os estudos de Florestan Fernandes (FERNANDES, 1980, $1982,1986)$. Outras referências também indicavam a pluralidade de sentidos de participação, como Bertoncello (2007); de movimentos sociais surgidos, como Paoli (1995); de matrizes discursivas e de ação, como Sader (2002).
} 
Por isso, buscaremos compreender quais as visões de democracia que se circulavam no movimento corinthiano. Tal identificação nos permitirá responder a duas questões: i) quais eram os sentidos compreendidos e pretendidos para e com o movimento?; ii) a pluralidade de formas de participação que o movimento forjou permite distinguir a Democracia Corinthiana como um movimento participativo e democrático?

Enfrentar essas problemáticas é pensar uma forma de vínculo do esporte com a política, em uma conjuntura particular do futebol brasileiro: a Democracia Corinthiana. Nesta, os sentidos de participação que foram promovidos, em especial, para os jogadores de futebol, criaram uma janela histórica para a constituição desses atletas enquanto sujeitos não mais destituídos do direito ao poder. Contribuímos, com isso, para as pesquisas sobre o campo esportivo, focando-nos no prisma das relações de poder suscitadas dentro desse.

\section{Percurso metodológico}

Conduzimos nossa pesquisa a partir da contextualização do objeto para elaborar os nexos entre o olhar histórico e o sociológico. Com isso, trabalharemos as falas e entendimentos da Democracia Corinthiana não como um fato isolado, mas como produto e sujeito de um tempo histórico.

Além da revisão bibliográfica, realizamos entrevistas semiestruturadas com dois sujeitos desse período, o presidente do clube, Waldemar Pires, e o jogador Wladimir ${ }^{6}$. Outra fonte de depoimentos da Democracia Corinthiana foi a pesquisa nos suplementos esportivos dos principais jornais paulistas (O Estado de São Paulo e a Folha de São Paulo), no período de março de 1981 a março de 1985. Fizemos ainda a revisão desse recorte temporal no periódico esportivo Revista Placar, já que esta apresentava um

\footnotetext{
${ }^{6}$ Foram realizadas entrevistas semiestruturadas, com questões abertas como: "Como você definiria a democracia corinthiana?"e "Quais foram as conquistas do movimento?", "Que direito que a democracia corinthiana permitiu alcançar?" As entrevistas foram realizadas em 2012, em locais de preferência dos entrevistados. Ademais, entrevistamos apenas esses dois sujeitos, uma vez que eles nos forneceram um material que reafirmava o coletado nos jornais e revistas.
} 
interesse grande pelo movimento, expresso em diversos editoriais. Estes materiais foram escolhidos por serem as principais referências da imprensa esportiva, os principais jornais do estado e por contemplarem visões distintas, tanto de apoio quanto de oposição ao movimento corinthiano. Após separar todas as notícias sobre o Corinthians, selecionamos as que continham relatos e depoimentos dos jogadores, técnicos e dirigentes expressando como esses sujeitos entendiam a democracia na experiência corinthiana. Cumprida essa etapa, categorizamos suas respostas a fim de elucidar os significados mais recorrentes emitidos acerca do conceito de Democracia Corinthiana.

Para esta análise, apoiamo-nos nas considerações do historiador Jacques Le Goff (2003). O autor salienta que "tendo em vista que todo documento é ao mesmo tempo verdadeiro e falso, trata-se de pôr à luz as condições de produção e de mostrar em que medida o documento é um instrumento de poder" (LE GOFF, 2003, p. 525). Por isso, a escolha dos periódicos esportivos cumpriu em nossa pesquisa o papel de colocar em ordem ideias recorrentes e, em conflito, opiniões diversas sobre o assunto. A categorização dos significados atribuídos à democracia no movimento alvinegro ${ }^{7}$ foi realizada da forma como a bibliografia específica sugeria distinguilos. A seguir subdividimos o artigo em cinco tópicos: o primeiro, acerca das definições conceituais de democracia na literatura acadêmica; o segundo, o terceiro são dois quadros amplos nos quais se encaixam distintos significados de democracia definidos pelos sujeitos do clube alvinegro, seja como procedimentos institucionais ou como valores, que são duas dimensões do conceito que se complementam; no quarto item é apresentada uma contradição dessa democracia. O último item apresenta as considerações finais dessa pesquisa.

\section{Sobre o CONCETO DE DEMOCRACIA}

Moraes (2001) retomou Norberto Bobbio em suas reflexões sobre o sentido da democracia, uma vez que "a linguagem política é Alvinegro é uma menção às cores do uniforme do clube. Este termo é utilizado neste texto para se referir ao Corinthians. 
notoriamente ambígua. A maior parte dos termos usados no discurso político tem significados diversos", por "terem passado por longa série de mutações históricas" (BOBBIO, 1986 apud MORAES, 2001, p. 16). Por essa linha, o conceito de democracia pode ser entendido em muitos sentidos, agregando "a seu campo semântico concepções distintas e até opostas" (MORAES, 2001, p. 16).

No entanto, os anos de ditadura militar no Brasil fizeram com que surgisse uma expectativa unívoca com relação à democracia. A reivindicação por esta, contida na agenda da campanha das "Diretas Já", confluiu num sentido pretensamente universal, homogeneizando os distintos significados contidos nas aspirações democráticas dos movimentos populares, sindicais e partidários. Essa homogeneização ganha espaço no debate teórico com o texto de Carlos Nelson Coutinho (1979), no qual o autor afirma que a democracia, no sistema capitalista, teria o papel fundamental de construir os pressupostos políticos do socialismo. $\mathrm{O}$ autor reconheceu que existiam diferenças nas concepções e sentidos da democracia entre as correntes que se propunham a representar os interesses populares, contudo, salienta que ela é "aquilo que une a todos os oposicionistas, ou seja, a luta pela conquista de um regime de liberdades políticos-formais que ponha definitivamente termo ao regime de exceção" (COUTINHO, 1979, p. 34).

O valor universal da democracia é identificado no Brasil, segundo a visão de Coutinho (1979), como o consenso construído a partir das liberdades concedidas no processo de distensão do regime militar, que culminou na campanha das "Diretas Já". Segundo ele, não se podia crer que alguma formação popular responsável pudesse colocar "em dúvida a importância dessa unidade em torno da luta pelas liberdades democráticas tais como essas são definidas, entre outros, no atual programa do MDB" (COUTINHO, 1979, p. 34). Essa visão é criticada por Moraes, em função de não se poder atribuir à democracia um valor unívoco, universal e/ou consensual e também por entender que dentro do processo de reivindicação da

${ }^{8}$ Movimento Democrático Brasileiro, partido de oposição no regime militar.

Movimento, Porto Alegre, v. 20, n. 01, p.81-101, jan/mar de 2014. 
democratização brasileira, os sentidos e rumos que se pretendiam com tal luta não eram unânimes ${ }^{9}$. Reconhecer o "valor universal" da democracia não tornava mais explícito seu sentido e tampouco aumentava seu estatuto de verdade, apenas demonstrava um consenso, que não registrava inerentemente um conteúdo prático (MORAES, 2001, p. 16).

Essa reflexão chama atenção para os diferentes sentidos de democracia. Deste modo, mesmo que a entendamos enquanto 'forma', isto é, mudança ou distensão nas relações políticas, é necessário observar as decorrências desse processo, ou seja, qual é o conteúdo a ser defendido. Demonstrando isso, a pesquisa de Moisés (2010), sobre a análise da democracia em distintas falas e segmentos populacionais, examinou as diferentes compreensões de democracia pelos brasileiros. Neste estudo, ele concluiu que a definição de democracia explicitada pelas pessoas "está associada, por uma parte, com o seu apoio normativo ao regime, isto é aos ideais que ele envolve e, por outra, com as expectativas que ele suscita a respeito do desempenho prático de suas instituições, como meios de realizar aqueles ideais" (MOISÉS, 2010, p. 302).

A seguir, iremos explicitar os significados de democracia atribuídos pelos sujeitos na Democracia Corinthiana. As falas foram selecionadas em duas categorias: termos procedimentais e a valores relacionados ao conceito ${ }^{10}$. No primeiro caso, analisamos a forma como a democracia era entendida como procedimento de funcionamento e como este modus operandi foi implementado. Nesse caso, estamos nos referindo ao estabelecimento de condições mínimas para um funcionamento democrático, definidos por Moisés

\footnotetext{
${ }^{9}$ Florestan Fernandes enumera três setores que defendiam diferentes rumos para a reabertura política: os militares do interior do regime, que buscavam a transição como distensão da ditadura. Em segundo lugar, havia o PMDB, que representava, para o autor, o setor "liberal" da ditadura, que, como oposição interna ao regime, percebeu que "seu ardor revolucionário renderia maiores dividendos se eles continuassem à testa do governo" (FERNANDES, 1986, p. 19). Em terceiro lugar, os movimentos políticos populares e sindicais, que poderiam aproveitar "o rancor contra a ditadura e a consciência geral da necessidade de mudar profundamente como ponto de partida de um transformação estrutural da sociedade" (FERNANDES, 1986, p. 28).

${ }^{10} E$ preciso esclarecer que tais categorias são analíticas. Não há uma separação absoluta entre as definições, de modo que, na realidade, elas mais se misturam, do que se diferenciam. Entretanto, a fim de organizar os significados de democracia obtidos na pesquisa, optamos por diferenciá-los em categorias.
}

Movimento, Porto Alegre, v. 20, n. 01, p.81-101, jan/mar de 2014. 
(2010) como competição democrática, direito à contestação, votações livres, regulares, competitivas e abertas. Em segundo lugar, analisamos os valores contidos na democracia, a partir de como ela era compreendida em termos de seus princípios mais importantes. Tal perspectiva, complementar à primeira, é entendida como a obtenção dos conteúdos e resultados esperados, nos quais se destacam dimensões como respeito às liberdades civis e aos direitos políticos e sociais (DIAMOND, MOLINO apud MOISES, 2010). Contudo, mais uma dimensão, de oposição às demais, foi encontrada como resposta, representando um momento de contradição da experiência democrática corinthiana.

\section{DEMOCRACIA COMO PROCEDIMENTO E GESTÃo dO CLUBE}

Em 1989, segundo Moisés (2010), 43,9\% dos brasileiros dizia preferir a democracia à ditadura como regime político ${ }^{11}$. No caso dos jogadores corinthianos, havia uma expectativa grande com a democracia, o que ficou patente a partir do final de 1982, com as declarações acerca da conquista do campeonato paulista, e com a eleição interna para presidência do clube em $1983^{12}$.

No entanto, antes destas circunstâncias, em 1981, o presidente do Corinthians, Waldemar Pires, já anunciava que sua gestão adotaria procedimentos de funcionamento que ele considerava mais democráticos. Naquele ano, tais mudanças eram referidas pelo presidente como "abertura", relacionada à descentralização e à proximidade entre os jogadores, com o intento de construção de uma gestão que englobasse profissionais especializados para comandar os diferentes departamentos (ISIDORO, 1981).

\footnotetext{
${ }^{11}$ Moisés (2010) baseou-se nos dados da pesquisa "Democratização e Cultura Política". Além dos brasileiros que preferiam democracia; $19,4 \%$ preferiam ditadura; $21,3 \%$ eram indiferentes; e $15,7 \%$ não responderam. $\mathrm{O}$ ano em que foi realizada a pesquisa estava inserido no cenário geral da década de 1980, demarcado pelo embate entre democracia e ditadura. Como breve comparação da mudança desse cenário, os dados em 2006 eram: 71,4\% preferiam a democracia, enquanto $14,2 \%$ a ditadura; e apenas $6,9 \%$ eram indiferentes.

${ }^{12} \mathrm{~A}$ notícia do título paulista de 1982, no jornal Folha de São Paulo chamou-se "Vitória da Democracia, diz Sócrates" (VITÓRIA, 1982b). O jornal O Estado de São Paulo noticiava "Vitória da Abertura" e "Eliminação da concentração" (VITÓRIA, 1982a; ELIMINAÇÃO, 1982).
}

Movimento, Porto Alegre, v. 20, n. 01, p.81-101, jan/mar de 2014. 
Em 1983, após a eleição interna do clube, Waldemar Pires afirmou que: "A descentralização será intensificada [...]. O resultado das eleições respalda a administração descentralizada [...] e nos autoriza a aprofundar essa mudança democrática" (VITÓRIA, 1983, grifos nossos). Esse seu entendimento de democracia como "descentralização" autorizava os vice-presidentes a organizarem autonomamente suas áreas de competência. Temos duas decorrências dessa concepção. A primeira foi que descentralizar a gestão do clube, segundo Santos (1990), significou torná-la mais compatível com o funcionamento profissionalizado de uma empresa. É justamente nesse aspecto que reside, para o presidente Waldemar Pires, o aprofundamento da democracia. Esta apresentava um significado particular, compreendida, por ele, como o movimento empreendido de profissionalização da gestão, uma vez que a decorrência disso era não centralizar a totalidade das decisões em um presidente, garantindo uma relativa autonomia de cada departamento.

Esta forma de organização do clube, pensada a partir da formação de uma burocracia especializada, não tem relação direta e, tampouco, necessária com a democracia, por mais que Waldemar Pires tenha a denominado assim. Na teoria Weberiana, a formação de uma burocracia é condição necessária para que um tipo ideal de dominação legítima se constitua, a dominação racional legal. Por dominação, o autor refere-se à "probabilidade de encontrar obediência para ordens específicas (ou todas) dentro de determinado grupo de pessoas", pressupondo a constituição de uma autoridade que tem poder de mando (WEBER, 1999a, p. 139). O caráter legítimo é dado quando há aceitação da dominação por parte dos dominados (WEBER, 1999a). No caso da dominação racional/legal, "o portador individual do poder de mando está legitimado por aquele sistema de regras racionais, sendo seu poder legítimo na medida em que é exercido de acordo com regras" (WEBER, 1999b, p. 197-198). Conforme demonstra o raciocínio de Weber, a conformação de uma burocracia se relaciona em primeiro lugar a essa forma de dominação, que, no exemplo corinthiano, possuía um caráter legítimo, frente ao grupo de jogadores. 
Em segundo lugar, a autonomia do departamento de futebol possibilitou a Adilson Monteiro Alves, vice-presidente de futebol (desde novembro de 1981), implantar votações entre os jogadores e a comissão técnica para a tomada de decisões. Neste caso, a obtenção de resultados positivos, como a obtenção do título do bicampeonato paulista, ajudou a conquistar também o apoio do conselho deliberativo para a gestão de Adilson. Dessa forma, mais do que uma defesa incondicional do modelo implantado no departamento de futebol, o presidente do clube alvinegro enfatizava os benefícios promovidos, o que garantiu a Adilson sua permanência.

Adilson Monteiro Alves explica o surgimento da democracia a partir de uma proposição de sua autoria numa reunião de 1981, relatada por ele como: "propus: vamos discutir a partir daí. Eles toparam. E a coisa colou" (TRAVAGLINI, 1983b). Percebe-se o surgimento da participação dos jogadores como algo que não foi gestado como reivindicação do próprio grupo, mas como uma sugestão do dirigente, incorporada a partir de uma consulta ao plantel para referendar seu método de trabalho.

Uma das lideranças do movimento, o jogador Sócrates, defendia como principal aspecto da vivência democrática no Corinthians a questão do voto, uma ação concreta da democracia (SOCRATES; GOZZI, 2002, p. 67). Para ele, isso se configurava como um processo de formação política, que culminaria num espaço de cidadania privilegiado para o atleta:

Qualquer questão era levada a voto. Qualquer um podia apresentar um assunto para votação. Quando viajar? A que horas viajar? Onde concentrar? Tudo era discutido. [...] Gradativamente, nós começávamos a mostrar para as pessoas com as quais nos relacionávamos profissionalmente que o voto delas era fundamental (SOCRATES; GOZZI, 2002, p. 67-68).

A vivência democrática se concretizava para Sócrates na discussão de "todos os assuntos, desde relacionados à profissão até a situação em que o país se encontra" (SOCRATES; GOZZI, 2002, p. 67). A escolha de um jogador da equipe para o cargo de técnico 
da equipe foi considerado por Sócrates o ápice, "sendo a prova mais contundente de que a democracia está instalada" (SOCRATES; GOZZI, 2002, p. 67). As votações possibilitavam a democracia vivenciada em sua forma participativa, segundo a qual a tomada de decisão era realizada diretamente pelos próprios agentes (BOBBIO, 2000) $)^{13}$.

No entanto, por mais que os procedimentos de votação fossem importantes, uma observação é prudente. Segundo Moraes (2001), a democracia não pode ser vista enquanto um valor absoluto em si mesmo. Este autor critica a visão de Coutinho (1979), como valor universal, ao registrar que toda a forma democrática possui inexoravelmente um conteúdo prático que deve ser analisado, para além de um modelo de funcionamento político.

É nesse sentido que cabe a fala de Wladimir, no momento de sua eleição conjunta com Zé Maria, conselheiro do clube, em que situa esta eleição específica enquanto um aspecto de cogestão que dava seus primeiros passos. Para esee sujeito, é justamente nesse ponto que poderia fazer avançar a experiência democrática (A DEMOCRACIA..., 1983b), pois

nos trouxe a possibilidade de, no futuro, estreitar ainda mais a nossa participação, junto à diretoria do clube. Com isso, podemos afirmar uma participação mais efetiva, mais ativa, dos jogadores com a política do Corinthians [...] permitindo que as discussões sejam livres e todas as vozes possam ser ouvidas sem discriminação (VITÓRIA, 1983).

Nesse caso, os depoimentos de Wladimir para a Revista Placar, que enfatizam o aspecto por ele denominado de "cogestão", demonstram que ele entendia o sentido democrático da experiência como a participação no conselho deliberativo, pois é lá que os jogadores estariam representando seus interesses na disputa de poder do clube. De tal modo, só as votações no interior do departamento

\footnotetext{
${ }^{13}$ Segundo Bobbio (2000, p. 18), existem diferenças entre a forma como a democracia foi pensada, chamada por ele de "ideal", e como ela foi constituída na realidade, como a "matéria bruta". Uma delas é que em sua forma ideal, a democracia prezava por ser participativa, direta, elemento que, na matéria bruta, tornou-se inviável no sistema governativo. Deste modo, a democracia participativa existiu historicamente apenas em momentos ou espaços pontuais.
} 
do futebol, para o jogador, não bastavam. Ainda que os aspectos anteriores remetessem a procedimentos de democracia, é a cogestão que se encaixaria mais exatamente numa visão mais procedimentalista, na qual tornava-se possível a competição, a participação e a contestação pacífica do poder (MOISÉS, 2010) .

\section{LIBERDADES E RESPONSABILIDADE COMO VALORES DA DEMOCRACIA.}

As pesquisas de Moisés (2010) demonstram que, em 1989, $40,4 \%$ dos brasileiros relacionavam democracia a valores ligados às liberdades. Ajustificativa para este percentual, na análise do autor, é de que a percepção da falta delas naquele momento influenciou as respostas. Tal como na pesquisa de Moisés, nos conceitos enunciados pelos sujeitos da Democracia Corinthiana, os valores relacionados às liberdades estavam presentes, contudo, com a adição de uma derivação, a responsabilidade.

Para Adilson Monteiro Alves, "não existia autoridade absoluta, mas sim liberdade e responsabilidade." (CASAGRANDE, 1983). Para tal dirigente, o significado de democracia pode ser identificado a partir de sua resposta à Revista Placar, em que esta questionava se não existia a possibilidade de o plantel decidir sobre a não necessidade de preparação física. Para esta questão, Adilson respondeu: "aí deixa de ser democracia, passa a ser anarquia, passa a ser um grupo de incompetentes e irresponsáveis. Aresponsabilidade é um fundamento da democracia" (A DEMOCRACIA.., 1983c). Wladimir afirmava que a liberdade advinda desse processo permitia com que os jogadores pudessem decidir sobre o seu lazer, e pudessem exercê-lo abertamente na medida em que se responsabilizariam pelas consequências $^{14}$.

Uma visão que abrange também a questão da responsabilidade, ainda que mais coercitiva, é a do técnico Mário Travaglini, na qual o

\footnotetext{
${ }^{14}$ Wladimir, em entrevista em 10/03/2012, afirmou que "foi maravilhoso porque a gente sabia que se a gente perdesse, estava na roça, ia acabar. lam atribuir tudo a não concentração. $O$ pessoal terminava o treino e ficava no Bar da Torre, lá no Parque São Jorge, e tomavam uma cerveja, o Sócrates, o Juninho, Casagrande. A gente fazia tudo às claras, não tinha nada para esconder de ninguém"
}

Movimento, Porto Alegre, v. 20, n. 01, p.81-101, jan/mar de 2014. 
sentido democrático estava relacionado ao seu estilo de trabalho, reconhecido pelo fato de ele não gritar, respeitar e ouvir a opinião do jogador sobre as táticas de jogo. Segundo o treinador, essa era a essência da democracia, que "Eu implantei, e o Adilson veio logo depois". Segundo ele, sua forma de trabalho representava que "Não sou paternalista. Sou coerente. [...] Democracia, afinal, é isso. Dar condições para que o grupo se fiscalize em seu próprio benefício" (A DEMOCRACIA..., 1983a). Este trecho vincula sua forma de trabalho democrática à sua concepção de responsabilidade.

Vincular responsabilidade a democracia não era exclusividade do fenômeno corinthiano. Autores de teoria democrática, como Guilherme O'Donnell (2011), relacionam a primeira ideia a este tipo de regime. Para o autor, a fim de que se estabeleçam competições limpas para o exercício de poder, apenas a existência de um mecanismo de voto não é o suficiente. São necessários outros dispositivos de liberdades, como o de expressão. Entretanto, a existência de algumas liberdades pode anular a de outras, de modo que, para que isso não ocorra, são fixados limites de juízo acerca das mesmas (O'DONNELL, 2011). É a partir do estabelecimento desses limites, internos e externos, que podemos encontrar as definiçõos de democracia elencadas acima. São eles que amparam as liberdades e fazem parte do jogo democrático, no qual se "obriga, necessariamente, a um compromisso com o entendimento de que homem (sic) é, ou pode converter-se em, um agente responsável, capaz de compreender e cumprir as normas e ser responsável por suas faltas" (FULLER, 1994, apud O'DONNELL, 2011, p. 44).

Dessa forma, a responsabilidade ressaltada como complemento à liberdade é componente da democracia. Tais elementos eram constantemente enfatizados pelos sujeitos do movimento alvinegro para se diferenciar de uma ideia corrente que relacionava democracia ao sentido mais corriqueiro de anarquia - como fica evidente na fala de Adilson que abre esse tópico ${ }^{15}$. No contexto de regime militar, as liberdades estavam restritas, de modo que a vivência

\footnotetext{
${ }^{15} \mathrm{~A}$ fala é a seguinte: "aí deixa de ser democracia, passa a ser anarquia, passa a ser um grupo de incompetentes e irresponsáveis. A responsabilidade é um fundamento da democracia"
} 
delas poderia suscitar dúvidas sobre o seu conteúdo, o que alimentaria visões equivocadas sobre a mesma. Daí a necessidade de se enfatizar constantemente que sujeitos de direito também são de deveres, de modo que essa concepção precisava ser divulgada e aceita, firmando uma ideia de democracia que não se contrapusesse à ordem.

\section{CONTRADIÇõES DE UMA DEMOCRACIA}

As distintas concepções de democracia podem se complementar, mas essa não é uma relação necessária, de tal modo que, muitas vezes, tais conceitos podem ser até mesmo opostos (MOISÉS, 2010), como ocorreu na Democracia Corinthiana. Algumas opiniões externas ajudam-nos a compreender os diferentes sentidos que se apresentavam para ela. $\mathrm{O}$ editorial do jornal Folha de São Paulo, focando outro aspecto, como uma metáfora da realidade, afirmava que a experiência alvinegra manifestava algo diferente,

O que há de fato no Corinthians é simplesmente a tentativa de substituir a disciplina do colégio interno a qual eram submetidos os jogadores - ali como em todos os clubes - por um regime adulto, vale dizer, baseado na autodisciplina. E, ligada a isso, uma experiência de participação dos atletas referente à equipe que integram (EDITORIAL, 1983).

Essa ideia de contraposição de formas de disciplina pode ser analisada a partir das concepções de Foucault. Este autor afirma que disciplina é um modo de exercer poder, e este último é uma relação de força. Sendo assim, ainda que se mude de um modo imposto externamente para um mais internalizado, o que se deseja com a democracia pautada pela disciplina é que os jogadores ou cidadãos aprendam e se sujeitem a formas de exercício de poder e a relações desiguais de força (KOHAN, 2003). Aproximando-se deste ponto de vista, a continuação do editorial expandia essa ideia: "Realisticamente, a Democracia Corinthiana já teria sido um sucesso 
se provar que a dignidade dos jogadores não é incompatível com a boa administração nem com a disciplina esportiva" (EDITORIAL, 1983).

O técnico Mário Travaglini, que concebia sua forma de atuar pautada pelo respeito ao jogador e pela exigência de responsabilidade, afirmava que este estilo não era novidade em seu trabalho: "essa vivência democrática e aberta que tivemos neste ano e meio não me foi novidade. Sempre agi assim, seja no Palmeiras, no Vasco da Gama ou no Fluminense" (TRAVAGLINI, 1983b). Nessa fala, o técnico expressa que inicialmente não havia nada que tornasse a democracia no Corinthians particular ou excepcional. No entanto, esta forma de exercício do poder, em sua visão, acabou saindo do seu domínio, pois "quando se lançou o slogan 'democracia' na eleição do clube, em março, a coisa abriu mais e, claro, houve mais cobrança. [...] Eu mesmo senti que estava começando a me desgastar, a ser cobrado demais, e talvez a exigir demais." (OS TÉCNICOS..., 1983). Fica evidente que, para ele, democracia não era exatamente como ele planejava definir seu trabalho, uma vez que este declinou logo após tal denominação.

Um pouco mais incisivo que Mario Travaglini, outro técnico da Democracia Corinthiana, Jorge Vieira, afirmava que a disciplina deveria estar presente na democracia, relacionando-a à hierarquia. Desde sua contratação pelo clube alvinegro, ele estabeleceu bases de contrato que evidenciassem que ele não perderia o poder de decisão sobre os jogadores "sou um homem de diálogo, mas tudo tem limite. Existe a última palavra, o poder de decisão que é do técnico. Tem que haver disciplina, respeito e hierarquia. Sem isso não existe progresso"(JORGE, 1983). Para este, "Eu faço minha democracia. Eu é que determino o que deve ser feito, e os jogadores têm acatado"(E A DEMOCRACIA..., 1983).

Ainda que Jorge Vieira aceitasse discussões e votações, suas falas transcritas demonstram uma concepção de democracia na qual a hierarquia era absoluta, pois não permitia que houvesse contestação do poder. Quando ele afirma que fazia sua democracia, nega a existência de procedimentos pré-definidos que organizariam o 
funcionamento da mesma, garantindo-a. Nesse caso, ele toma para si as rédeas da equipe, de modo a anular a democracia participativa, promovendo uma gestão personalista, que mais se aproxima de uma autocracia do que efetivamente de uma democracia.

A demonstração das contradições dessas concepções de Jorge Vieira e de Mário Travaglini fica explícita em determinada ocasião, quando Sócrates chegara atrasado para um treino. Jorge Vieira tentou agir de acordo com sua democracia, fundada na hierarquia, exigindo uma punição para o jogador. Nesse episódio, ele pediu à diretoria o estabelecimento de uma tabela de multas por infrações desse tipo, o que foi confirmado, em entrevista à Revista Placar, por Adilson Monteiro Alves. $\mathrm{O}$ vice-presidente disse haver uma regulamentação para essas punições, "discutida em grupo e aprovada pelos jogadores" (TIMÃO, 1983). Entretanto, o jogador Biro-Biro afirmava que desconhecia o regulamento e a reunião que o aprovara (TIMÃO, 1983). Tal episódio demonstra uma das contradições que se estabeleceu durante a Democracia Corinthiana, confirmando a visão de gestão autoritária exposta a partir das falas de Jorge Vieira e Mário Travaglini ${ }^{16}$.

Este exemplo demonstra também um momento não democrático da experiência corinthiana. Conforme apontou Coutinho (1979), em uma definição ampla de democracia, esta é entendida como uma forma baseada "numa dialética do pluralismo", isto é, na existência de uma autonomia dos sujeitos coletivos (COUTINHO, 1979, p. 40). Este elemento se perdeu nas contradições da experiência corinthiana, se opondo, portanto, a seu sentido democrático. Por mais que estas concepções estivessem restritas aos técnicos, em última instância, eram eles que organizavam a equipe e, como no caso emblemático de Casagrande, tinham o direito de cortar jogadores.

\footnotetext{
${ }^{16}$ Outro momento de contradição da Democracia Corinthiana ocorreu no caso da demissão de Jorge Vieira, em que este tentou excluir Casagrande de uma delegação, mas, na medida em que não obteve o respaldo de Adilson Monteiro Alves, acabou por se demitir. Neste episódio, a diretoria decidiu punir Casagrande, suspendendo-o por dois meses da equipe e depois colocandoo à venda, o que desagradou a vontade do jogador. A contratação do goleiro Leão, cuja decisão deu-se sem a participação da maioria do grupo de jogadores, também ilustra os limites e contradições dos sentidos de democracia contidos no movimento.
} 


\section{CoNSIDERAÇõEs FINAIS}

Os diferentes significados obtidos com as falas dos sujeitos sobre a Democracia Corinthiana tocam principalmente as questões referentes aos procedimentos democráticos, nos quais foi percebida uma mudança significativa - permitida a partir da autonomia concedida ao departamento de futebol - que foi a introdução das votações. Outras falas evidenciam concepções relacionadas aos valores da democracia, como as liberdades - fruto do longo período da história brasileira no qual elas eram vivenciadas de forma restrita - e acentuam o cenário de paternalismo no futebol, no qual os jogadores eram desprovidos da faculdade de sujeitos políticos. Ainda, percebemos que as concepções e a prática do movimento por vezes se tornaram contraditórias.

Pode-se compreender que a democracia contida no movimento alvinegro não absolutamente se opunha às formas desiguais de poder estabelecidas historicamente no futebol, que tornavam o jogador sujeito atomizado e elo mais fraco desta estrutura. Por mais que fosse admitida sua participação - considerada democrática - esta não se dava a partir de formas mais radicais de divisão do poder, como a participação de mais jogadores no conselho deliberativo do clube ou nas demais instâncias de comando. Nesse sentido, a participação pode ser entendida também não como uma alternativa ou transformação radical na democracia, mas como um complemento, em termos quantitativos, sem alteração concreta da estrutura de poder estabelecida, uma vez que, assim como em alguns regimes representativos, ainda que as possibilidade de fazer parte da escolha do representante aumentem, isso não significa necessariamente um correlativo aumento no poder do indivíduo em tomar parte das decisões (BOBBIO; MATTEUCCI; PASQUINO, 1986).

Ainda que contivesse contradições, a pluralidade contida na Democracia Corinthiana permite vislumbrar um momento no qual o esporte e a política estabeleceram uma relação excepcional entre si. Neste caso, tal relação não veio no sentido de instrumentalizar o 
esporte a favor de um regime político ou outro ${ }^{17}$, mas possibilitou que os jogadores se colocassem como sujeitos históricos e políticos. Sobretudo, tal experiência trouxe à tona a possibilidade de alguma forma de participação no poder, seja interno ao clube, aos treinos, ao direito de opinião ou mesmo de se conscientizarem e exercerem seu papel de cidadãos, sendo esse aspecto um possível legado que a Democracia Corinthiana deixou ao futebol brasileiro.

\footnotetext{
${ }^{17} \mathrm{Na}$ educação física brasileira, em meados da década de 1980, se fortalecia um debate com críticas ao esporte de alta competição, em função de sua instrumentalização para servir à manutenção do status quo. Tais teóricos, influenciados pela teoria crítica, denunciavam a forma como o esporte era utilizado para o reforço de valores do sistema capitalista (BRACHT, 1986). Esta crítica também estava presente naqueles que relatavam o papel que a educação física brasileira, através de seu conteúdo hegemônico esporte, cumpriu de apoio à ditadura militar (CASTELLANI FILHO, 1988). Outros autores ainda trataram de temáticas semelhantes como Ghiraldelli Junior (1988) e Oliveira (1993).
} 


\section{Significados de democracia para los sujetos de la Democracia Corinthiana}

Resumen: Esta investigación se centra en la Democracia Corinthiana, un movimiento de un grupo de jugadores y directores del Sport Club Corinthians Paulista, en el período de 1981-1985. El proposito de este artículo es analizar los significados atribuidos por los jugadores, entrenadores y directores a la democracia en el movimiento. A partir de una revisión de la literatura acerca de la democracia, dos entrevistas y una investigación en los periódicos, que encontramos las declaraciones de los sujetos que se referían a como ellos entendían el movimiento. Los resultados muestran respuestas que variaron en términos de defensas de procedimientos de tomada de decisiones y de los contenidos de los logros, además de algunos puntos contradictorios. Por lo tanto, no se puede afirmar que la democracia en la Democracia Corinthiana tenía un único sentido.

Palabras-claves: Democracia Corinthiana. Sociologia del deporte. Fútbol. Democracia.

\footnotetext{
Meanings of democracy to the social actors of Democracia Corinthiana

Abstract: This paper is about Democracia Corinthiana, a movement from a group of football players, managers and directors of Sport Club Corinthians Paulista, in the period of 1981 to 1985 . The aim is to analyze different meanings of democracy to the players, managers and directors, who were the movements' social actors. From a bibliographic revision about democracy, two semi-structured interviews and a historical research in newspaper that we picked up statements from those social actors, that had implied their democracy conception on the corinthians' experience. As results, we found statements about democracy that fluctuates from a defense of the movements' procedures of decision making, until its values, besides one point that denies the other ones. Thus, we can't predicate a unique sense on democracy at Democracia Corinthiana.

Keywords: Democracia Corinthiana. Sociology of sports. Football. Democracy.
} 


\section{REFERÊNCIAS}

BERTONCELO, E. A campanha das diretas e a democratização. São Paulo: Humanitas, 2007.

BOBBIO, N.; MATTEUCCI, N.; PASQUINO, G. Dicionario de politica. 2. ed. Brasília, DF: Ed. Universidade de Brasilia, 1986.

BOBBIO, N. O futuro da democracia: uma defesa das regras do jogo. 7. ed. São Paulo: Paz e Terra, 2000.

BRACHT, V. A criança que pratica esporte respeita as regras do jogo... capitalista. Revista Brasileira de Ciências do Esporte, São Paulo, v. 7, n. 2, p. 62-68, jan. 1986.

CASAGRANDE joga e Zé Maria elogia time. Folha de São Paulo, São Paulo, p. 28, 9 abr. 1983.

CASTELLANI FILHO, L. Educação física no Brasil: a história que não se conta. Campinas: Papirus. 1988.

COUTINHO, C. N. A democracia como valor universal. Encontros com a Civilização Brasileira, Rio de Janeiro, n. 9, mar. 1979.

A DEMOCRACIA do Morumbi. Revista Placar, São Paulo, n. 682, p. 30, 17 jun. 1983a.

A DEMOCRACIA em debate. Revista Placar, São Paulo, n. 675, p. 18, 29 abr. 1983b.

A DEMOCRACIA se consolida. Revista Placar, São Paulo, n. 672, p. 17, 8 abr. 1983c.

E A DEMOCRACIA continua. Revista Placar, São Paulo, n. 685, p. 17, 8 jul. 1983. EDITORIAL. Folha de São Paulo, São Paulo, p. 2, 1 abr. 1983.

ELIMINAÇÃO da concentração. O Estado de São Paulo, São Paulo, p, 21, 14 dez. 1982.

FERNANDES, F. Brasil: em compasso de espera: pequenos escritos políticos. São Paulo: HUCITEC, 1980.

FERNANDES, F. A ditadura em questão. São Paulo: T. A. Queiroz, 1982.

FERNANDES, F. Nova República? Rio de Janeiro: Zahar, 1986.

GUIRALDELLI JUNIOR, P. Educação Física progressista. São Paulo: Loyola. 1988. 
HUNTINGTON, S. P. A terceira onda: a democratização no final do século $\mathbf{X X}$. São Paulo, SP: Ática, 1994.

ISIDORO Matheus é candidato pela oposição. O Estado de São Paulo, São Paulo, p. 34, 26 mar. 1981.

JORGE Vieira no Corintians. Folha de São Paulo, São Paulo, p. 24, 4 maio 1983.

KOHAN, W. O. Infancia: entre educação e filosofia. Belo Horizonte: Autêntica, 2003.

LE GOFF, J. História e memória. Tradução de Irene Ferreira, Bernardo Leitão, Suzana Ferreira Borges. 5. ed. Campinas: Editora da UNICAMP, 2003.

MOISES, J. Á. Os significados da democracia segundo os brasileiros. Opinião Publica, Campinas, v. 16, n. 2, p. 269-309, 2010.

MORAES, J, Q. Contra a canonização da democracia. Crítica Marxista, Campinas, n. 12, 2001.

O'DONNELL, G. Democracia, agência e estado: teoria com intenção comparativa. São Paulo: Paz e Terra, 2011.

O'DONNELL, G. SCHMITTER, P. Transições do regime autoritario: America Latina. São Paulo: Vertice, 1988.

OLIVEIRA, V. M. As pedagogias do consenso e do conflito: a produção teórica da educação física brasileira nos anos 1980. Revista Brasileira de Ciências do Esporte, São Paulo, v. 14, n. 3, 1993.

PAOLI, M. C. Movimentos sociais no Brasil: em busca de um estatuto político. In: HELMANN, M. (Org.). Movimentos sociais e democracia no Brasil. São Paulo: Marco Zero, 1995

SADER, E. Quando novos personagens entram em cena. São Paulo: Paz e Terra, 2002.

SANTOS, L. T. Futebol empresa e a democracia corinthiana: uma administração que deu dribling na crise. 169 f. Dissertação (Mestrado) - Instituto de Filosofia e Ciências Humanas, Universidade Estadual de Campinas, Campinas, 1990.

SÓCRATES; GOZZI, R. Democracia Corinthiana: a utopia em jogo. São Paulo: Boitempo, 2002.

OS TÉCNICOS discutem a democracia. Revista Placar, São Paulo, n. 677, p. 58, 13 maio 1983.

TIMÃO incomoda muita gente. Revista Placar, São Paulo, n. 690, p. 6, 12 ago. 1983.

TRAVAGLINI promete menos conversa e mais futebol. Folha de São Paulo, São Paulo, p. 22, 25 mar. 1983a. 
TRAVAGLINI sai, desanimado e desgastado. Folha de São Paulo, São Paulo, p. 28, 30 mar. 1983b.

UMA PROVA de democracia. Folha de São Paulo, São Paulo, p. 24, 19 abr. 1983.

VITÓRIA da abertura. O Estado de São Paulo, São Paulo, p. 21, 14 dez. 1982a.

VITÓRIA da democracia, diz Sócrates. Folha de São Paulo, São Paulo, p. 44, 12 dez. 1982b.

VITÓRIA da Democracia Corinthiana foi fácil. Folha de São Paulo, São Paulo, p. 13-14, 07 mar. 1983.

WEBER, M. Os tipos de dominação. In: Max Weber. Economia e sociedade. Brasília: Ed. Universidade de Brasília, 1999a. v. 1.

WEBER, M. Sociologia da Dominação. In: Max Weber. Economia e sociedade. Brasília: Ed. Universidade de Brasília, 1999b. v. 2.

Recebido em: 25.04.2013

Aprovado em: 16.09.2013

Movimento, Porto Alegre, v. 20, n. 01, p.81-101, jan/mar de 2014. 